\title{
Los «teatros» de La Patria (1849): la crítica teatral del joven Antonio Cánovas del Castillo
}

\author{
The «Teatros» of La Patria (1849): \\ The Young Antonio Cánovas del Castillo \\ and his Theatre Criticism
}

\author{
Irene Donate Laffitte \\ Centro Universitario Villanueva (UCM) \\ idonate@villanueva.edu \\ ORCID iD: http://orcid.org/0000-0002-9251-3967 \\ José Bernardo San Juan \\ Universidad Rey Juan Carlos \\ jose.bernardo@urjc.es \\ ORCID iD: http://orcid.org/0000-0001-9265-8499
}

\section{RESUMEN}

Las críticas de teatro que el joven Antonio Cánovas del Castillo firmó en 1849 para el diario La Patria no han sido analizadas hasta el momento. En este trabajo se ofrece su catalogación así como, a la luz de esas críticas, los criterios de juicio de Cánovas. De esta forma se muestra una faceta de la personalidad y, sobre todo, de la juventud del político. Su tarea como crítico de teatro añade una perspectiva poco conocida y de interés para los estudiosos del político-crítico.

Palabras Clave: Antonio Cánovas del Castillo; crítica literaria; literatura del siglo XIX; romanticismo; periódico La Patria.

\section{ABSTRACT}

Theater criticism that the young Antonio Canovas del Castillo signed in 1849 for the newspaper La Patria so far have not been analyzed. In this paper cataloging and, in the light of these criticisms, the criteria of literary judgment Canovas is offered. Thus a facet of personality and, above all, youth politician Antonio Canovas del Castillo is offered. His job as a theater critic adds a little-known political critic and of interest to scholars facet.

Key words: Antonio Cánovas del Castillo; Literary Criticism; 19th Century Literature; Romanticism; La Patria Magazine. 


\section{INTRODUCCIÓN}

La personalidad poliédrica de Antonio Cánovas del Castillo ha propiciado aproximaciones a su obra desde muy diversas perspectivas. La mayor parte de ellas se centran en su figura pública — no en vano fue ministro repetidas veces en un período de 30 años-, en su pensamiento político y en sus obras como historiador. Su faceta como literato ha merecido menos entusiasmo habida cuenta de la práctica confluencia de todos los críticos a la hora de describirlo como «autor menor». Al tratar su obra La Campana de Huesca, por ejemplo, el padre Blanco calificaba a Cánovas como «émulo poco feliz de Walter Scott» (1903: 266), el padre Cejador la consideraba «obra de aprendiz» (1910: 125) y ni Alborg (1980) ni Cecilio Alonso (2010) siquiera la mencionaron en sus volúmenes sobre historia de la literatura española. Similares juicios merecieron sus poesías. A todo ello debe unirse la circunstancia de que un genio tan señalado como el suyo no pudiera evitar juicios literarios que pasaran por alto los políticos. Así lo advertía Menéndez Pelayo, uno de los pocos defensores del Cánovas escritor: «más la perjudicó [a La Campana de Huesca] que la favoreció el prestigio de su autor, en quien continuamente se encarnizaba la importuna malevolencia de sus enemigos políticos» (1949: 417). Pero si su obra de creación ha sido poco estudiada, tampoco han merecido demasiada atención sus colaboraciones en la prensa, que únicamente han sido localizadas y datadas por M. del Pilar García Pinacho en su artículo «Cánovas y sus colaboraciones periodísticas» (Bullón y Togores, 1999: 329-344).

Es probable que la indiferencia sobre la actividad literaria de Cánovas haya sido la causa de la ausencia casi completa de atención sobre su labor crítica. Romero Tobar constituye una excepción. En su Panorama Crítico del Romanticismo Español no menciona a Cánovas como creador sino como crítico y, en esa faceta, considera, por ejemplo, que es interesante - aunque matizable - la opinión de Cánovas sobre El Estudiante de Salamanca (1994: 234) y le parece que es «todavía útil» la interpretación del costumbrismo que aparece en el libro de Cánovas sobre Estébanez Calderón (1994: 405).

En cuanto a la inicial crítica teatral de Cánovas en prensa, esta es la primera vez que se realiza una investigación detallada. En este artículo se ha realizado un análisis de las críticas de teatro que Cánovas publicó en el diario La Patria a lo largo de 1849. Además del trabajo bibliográfico, sustanciado en su catalogación, se ha elaborado, a través de la lectura de los propios textos en conjunto - por medio, por tanto, de una metodología inductiva-, un retrato de los criterios críticos de Cánovas. Con ello se añade luz a la cara menos conocida de este autor.

Además - y por más que las críticas publicadas en la prensa hayan sido objeto habitual de estudio en la historia de la literatura y de la crítica literariaalgunos autores (singularmente Celma Valero en La Pluma ante el Espejo, 1989, y en Literatura y Periodismo en las Revistas del Fin de Siglo, 1991) han 
defendido la oportunidad de volver a ellas en la medida en que aún se puede encontrar en su estudio pormenorizado contenidos que ayuden a una mejor comprensión del devenir de la crítica. Ya Emilia de Zuleta había advertido en el prólogo de la Historia de la Crítica Española Contemporánea la necesidad de un «un cúmulo de trabajos monográficos previos, sobre períodos y sobre autores» (1966: 9) que permitiera la elaboración de un retrato de conjunto. Zuleta hacía referencia a autores españoles, pero esos mismos trabajos especializados son los que, entre otros muchos aspectos y de forma muy modesta pero real, hacen posible las síntesis más universales de la crítica, como las ofrecidas en la Historia de la Crítica Literaria de David Viñas (2002) o en Sobre Crítica y Críticos de Alborg (1991).

\section{CÁNOVAS ESTUdiante Y PERIODISTA}

Cánovas llegó a Madrid en 1845. En la capital se encontró con el clima político de la llamada Década Moderada (1843-1855), ambiente propicio para el desarrollo de su carrera ya que frente a los convulsos años anteriores,

hay un ansia de consolidación y de sosiego. La divisa de la época no va a ser ya libertad, sino orden. Para el moderantismo, imperante en todo el decenio, ha pasado ya la época de las revoluciones; el trono de Isabel II está asegurado tras la derrota del carlismo, y ahora corresponde consolidarlo y atender a los «intereses materiales» (Seoane, 1996: 171).

Había abandonado su Málaga natal para estudiar la carrera de Derecho. Tenía 17 años. Fue acogido y apadrinado por su tío Serafín Estébanez Calderón, «El Solitario», periodista por quien — tal y como demostró años más tarde en El Solitario y su Tiempo (Cánovas, 1883) - siempre sintió admiración. Desde el principio reveló interés por el mundo de la cultura y la política y comprendió que los periódicos se habían consolidado como los principales órganos de influencia. La década de los cuarenta fue un período de transición que, a menudo, encontró al ciudadano sumido en la perplejidad y en medio del cual buscaba orientación en los periódicos.

Las de La Patria no fueron sus primeras colaboraciones. Ya en 1848 había aparecido su firma en El Semanario Pintoresco Español (Simón Díaz, 1946: 47) donde publicó un poema, un relato y varios artículos de tema histórico. Pero fue La Patria el primer medio en el que escribió regularmente. A principios de 1849 entró a formar parte de la redacción. Tenía 21 años. Dirigía el periódico Joaquín Francisco Pacheco. Su relación con Pacheco se consolidó con rapidez hasta el punto de que años más tarde se complacería «en respetar [a Pacheco] como maestro y en admirar como lo que es: como uno de los hombres cuyo talento más honra a su patria» (1868a: 219). 
En La Patria Cánovas se dedicó sobre todo a quehaceres relacionados con la literatura: los artículos sobre Teatros, la crítica de novelas y también algunos poemas. De entre todas sus colaboraciones de entonces, las críticas teatrales fueron las más frecuentes y homogéneas y, por tanto, son aquellas cuyo análisis permite ofrecer un retrato más completo de su pensamiento en torno al género dramático.

Los testimonios de aquellos que convivieron con Cánovas muestran un estilo de vida con dos facetas. Por un lado hablan del joven que pasaba horas leyendo y estudiando y por el otro del que frecuentaba las tertulias de los cafés. Su hermano Emilio, según cita Isabel Díez Ménguez, contó que se desvivía «para asistir al Ateneo, del que era socio, y en cuya biblioteca se pasaba en ocasiones casi días enteros» (Bullón y Togores, 1999: 346) y Antonio María Fabié, hijo de un íntimo amigo y colaborador de Cánovas, relató que, en el curso de 1849, el futuro político estudiaba una asignatura de Derecho y que «se pasaba por entonces el día y buena parte de la noche estudiando; salvo las horas de cátedra, las demás las invertía en la biblioteca particular de su tío El Solitario, que vivía en la calle de la Luna, la Nacional y la del Ateneo» (1928: 22).

Pero también su hermano Emilio lo recordaba en su vertiente más social:

\begin{abstract}
Por sus aficiones literarias quiso mi hermano ser presentado al gran Quintana, de quien recibió muy buenos consejos, concurriendo muy a menudo, casi diariamente, al Parnasillo o café del Príncipe; y con alguna frecuencia también al café de la Esmeralda, en la calle de la Montera, punto de reunión, como aquel otro, de escritores y poetas [...]. En el Parnasillo hizo amistad con autores dramáticos y literarios tan afamados como Hartzenbusch, Rodríguez Rubí, Florentino Sanz, Gil y Zárate, Ferrer del Río y Núñez de Arce; éste era el más joven de todos ellos. En el café de la Esmeralda conoció así mismo a Mariano Zacarías Cazurro, Antonio de Trueba, Luis Eguilaz, Carlos Ochoa, Luis Mariano de Larra, Carlos Pravía, Diego Luque, Vicente Barrantes, Enrique Cisneros, Núñez del Prado y Eduardo Gasset y Artime, todos jóvenes de gran mérito, con quienes hizo amistad (Bullón y Togores, 1999: 346).
\end{abstract}

A finales de 1849 pasó a ocupar el cargo de director de La Patria. Durante los años siguientes Cánovas escribirá en otra revista dirigida por Ángel Fernández de los Ríos, La Ilustración, Periódico Universal, cuyo prospecto se había anunciado en La Patria y que comenzaría su andadura en 1850. También está documentada, a través de anuncios insertados en La Patria (7/12/1849), la participación de Cánovas en la revista literaria Los Hijos de Eva. En esta primera etapa estuvo fuertemente ligado al periodismo y al teatro lo cual constituyó para él una gran escuela de aprendizaje de cara a su posterior vida política. Además le ayudó a clarificar su futuro profesional en favor de la política, según testimonio de Antonio María Fabié: 
Cuando terminó su labor [como director de La Patria] dijo Cánovas a mi padre: «Me gusta mucho el periodismo, pero jamás seré periodista profesional, pues es un negocio que nada produce en España, y expone a grandes quiebras; escribiré ocasionalmente en el porvenir aquí y allá, en provecho de la labor política que realice, pero nada más» (1928: 29).

El malagueño mantuvo un gran apego al teatro y siempre recordó con cierta nostalgia su labor de crítico en La Patria, a la cual se refieren sin duda estas palabras, incluidas en el prólogo que encabezó una selección de autores dramáticos: «Si alguien guardase memoria de los principios oscuros de mi carrera, bien podría testificar que el amor al arte dramático y a cuanto con él se relaciona, precedió en mí con mucho a todo aquello en que he gastado la vida después» (Cánovas, 1881: II).

\section{El DiARIO LA PATRIA (1849-1951)}

En los años de la Década Moderada la legislación sobre los periódicos conoció variaciones cada pocos meses aunque todas ellas compartían el signo de la restricción: las trabas para poder ser editor de diarios fueron en aumento con respecto a los años inmediatamente precedentes. Se incrementaron las multas y su cuantía y se alambicaron las normas sobre qué temas no debían ser tratados - fundamentalmente aquellos relacionados con asuntos de la Monarquía- (Seoane, 1983: 197). Son los años en los que en un clima de prensa política-ideológica comienza a destacarse en algunas cabeceras el aspecto exclusivamente informativo. En la prensa madrileña, y de acuerdo con las estadísticas de Correos, los periódicos moderados - entre los que se podría adscribir a La Patria - eran mayoría (44\%), frente al 30\% de los progresistas y el 25\% de los absolutistas (Cabrera, Elorza, Valero y Vázquez, 1975: 100). Según esas mismas estadísticas - y de acuerdo con los datos que ofrece León Roch (seudónimo de Francisco Pérez Mateos) — La Patria debía tirar en torno a 3000 ejemplares frente a las $12000 \mathrm{del}$ conservador El Heraldo o del absolutista $L a$ Esperanza (Roch, 1927: 170).

Cuando en enero de 1849 sale a la calle el diario La Patria, su director, Joaquín Francisco Pacheco, era ya una figura pública muy conocida. Al igual que el resto de empresas periodísticas de Pacheco, tuvo esta una existencia breve (1849-1951) y estuvo marcada por la excepcional personalidad de su mentor. Gómez Aparicio define a este periódico como «sumamente razonador y lógico en sus comentarios de política interior y exterior» y no duda en afirmar que, por eso mismo, «rayó a una altura que, hasta entonces, pocas veces había alcanzado la prensa española» (1967: 375).

En el ámbito político Pacheco se situó dentro del partido moderado en su tendencia más liberal como máximo representante de la corriente llamada 
puritana, grupo dentro del moderantismo que aspiraba, según M. ${ }^{a}$ Cruz Seoane, «a ser un partido conservador moderno, que asumiese y conservase las conquistas de la revolución» (1996: 172). Encabezando este partido, Pacheco ocupó la Presidencia del Consejo de Ministros entre marzo y agosto de 1847. Precisamente La Patria se fundará como ariete periodístico de esta parte puritana de los moderados con un tono general acorde con este talante. Era, pues, un periódico moderado, crítico con los gobiernos moderados.

Pacheco fue también poeta y dramaturgo. Escribió una veintena de poesías y tres dramas románticos: Alfredo, Los Infantes de Lara y Bernardo, estrenada esta última en 1849 y objeto de una elogiosa crítica de Cánovas en $L a$ Patria (18/3/1849). Al igual que le sucedería a Cánovas, su dedicación a la literatura fue ciertamente efímera porque pronto quedó ensombrecida por la política: «esa existencia artística que había sido mi ilusión y mis amores, había de pasar como un relámpago, para perderse en la vida azarosa de la política» (Pacheco, 1864-1865, II: 183). Sin embargo, él consideraba que sus orígenes literarios habían sido el origen y el motor de otro de los ejes sobre el que pivotó su actividad intelectual: su apasionada dedicación al periodismo, exaltada en 1845 en su discurso de ingreso en la Real Academia de la Lengua con el título Sobre el Periodismo en sus Relaciones con la Literatura (Pacheco, 1864-1865, II: 181-196):

Desertor como lo era de la literatura clásica, académica de nuestros padres, dediqué mis vigilias y mis esfuerzos a esa otra especie de literatura, militante y febril, que nos han traído las revoluciones, y que es hoy día un accidente necesario en el estado de nuestra sociedad. Me refiero, señores, al periodismo, creación de la presente época, signo y expresión de la actividad que nos devora (Pacheco, 18641865, II: 184-185).

\subsection{Literatura en La Patria}

Una práctica habitual de la prensa decimonónica fue la inserción de contenidos de carácter literario. A mediados de siglo los periódicos solían incluir tres clases de contenidos: por un lado era raro el periódico que no publicara folletines — que gozaban de gran aceptación popular-, además aparecían frecuentemente secciones con noticias de carácter práctico relacionadas con lanzamientos de libros y, sobre todo, con los estrenos en los diversos teatros y, por último, los artículos de carácter crítico en donde se enjuiciaban obras literarias, históricas, científicas, etc. A este último grupo, según se verá, pertenecían los Teatros de Cánovas.

La Patria incluía todos esos contenidos. En la parte inferior de la primera página solía aparecer la sección titulada «Folletín» en la que se publicaron 
novelas y creaciones literarias por entregas ${ }^{1}$ y críticas de novelas ${ }^{2}$ y de obras filosóficas, históricas y jurídicas ${ }^{3}$. Fue allí — con la excepción del publicado el 26 de diciembre de 1849- donde aparecieron los Teatros de Cánovas, de los que se hablará más adelante.

La sección «Crónica de Madrid», situada en las últimas páginas del periódico, ofrecía noticias breves de acontecimientos sucedidos o por suceder en la capital además de noticias relacionadas con el mundo teatral — compañías de actores, obras en preparación, obras estrenadas, reacciones del público, construcción y promoción de teatros, etc.- En la última página del diario estaban las secciones de «Anuncios»y de «Espectáculos». En la primera se anunciaron obras literarias de la misma editorial que el periódico y en la segunda las representaciones teatrales de las salas de Madrid.

\subsection{Los «Teatros» y la crítica literaria}

Desde la primera ojeada a La Patria resulta evidente la especial atención que se concedía al género dramático: se hablaba de los autores, actores, estrenos, reglamento de teatros, inauguración de salas, precio de localidades y demás, reflejándose así la gran afición del mismo público que leía el periódico, el público burgués, que demandaba información completa y detallada sobre su entretenimiento favorito.

${ }^{1}$ Las novelas publicadas por entregas en el año 49 fueron De Villahermosa a la China de Nicomedes Pastor Díaz (1/1/1849-12/1/1849), Las Confidencias de Alfonso de Lamartine (13/1/1849-15/2/1849. Se reanuda a lo largo del mes de marzo), El Collar de la reina de Alejandro Dumas (1/4/1849-15/6/1849), Lucio y el Asno, traducción libre de un relato griego (1/6/1849), El Soprano, cuento de J. Somoza (8/7/1849-10/7/1849), Alix, leyenda alemana de Octavio Feuillet (18/7/1849-22/7/1849), La Víbora, novela de Julio Lacroix, traducida por Emilio de Tamarit (25/7/1849-30/8/1849), Los mil y un fantasmas de Alejandro Dumas (1/9/1849-10/1/1850) y Flores Perdidas de N. Camilo Jover (23/9/1849). Los poemas fueron «A Italia» de Antonio Cánovas del Castillo (16/1/1849), «A...» de Antonio Cánovas del Castillo (4/2/1849), «A una mariposa», poesía de Fernando Pérez Casar (18/2/1849), «La última cena», poema de don Juan Nicasio Gallego, y «En la muerte de Jesús», soneto de F. P. A. (5/4/1849).

2 «Apuntes sobre la literatura americana» por A. Cánovas del Castillo (23/5/1849) y «La estrella del Sud», novela original de A. Magariños Cervantes, firmada también por Cánovas (24/7/1849).

${ }^{3}$ Dos artículos titulados «Crítica literaria: Revista de escritos filosóficos y políticos sobre las cuestiones del día I y II» (16/2/1849 y 21/2/1849), firmados por Cánovas; «El pleito de la medalla de oro», firmado por José Antonio de la Puente (4/3/1849); y tres artículos titulados «Crítica literaria: Discursos políticos sobre la legislación y la historia del antiguo reino de Aragón, por don Javier de Quinto, de la Academia de la Historia» por Antonio Cánovas del Castillo (23/3/1849, 31/3/1849 y 17/4/1849). 
Los Teatros de Cánovas se publicaron los lunes, desde el 8 de enero y hasta el 26 de diciembre de 1849. Según consta en la «Advertencia» que encabeza el número 288 del periódico (5/12/1849) Pacheco dejó la dirección a principios de diciembre y fue entonces cuando Cánovas pasó, simultáneamente, a ocupar el puesto de director y a abandonar la crítica teatral. En total publicó 18, en las que habló sobre 40 obras distintas y que firmaba bien con su nombre completo o su apellido, bien con las variantes «Antonio C. del Casti1lo», «A. C. del Castillo» o bien con las iniciales «A. C.» y «A. C. del C.».

Eran estos unos artículos extensos en los que, con motivo de los estrenos teatrales, se escribía su crítica. Se trataba de unos textos en los que aunque se podía hacer referencia a características de la representación y hasta a noticias de sociedad en torno al estreno, se buscaba fundamentalmente emitir un juicio sobre la obra. Dar noticia exclusiva sobre los estrenos de teatro estaba reservado, según se ha visto, a otras secciones. Aquí se contextualizaban las obras en la historia, se juzgaba su estilo, se citaba la obra escrita y con frecuencia se ofrecía una interpretación.

La crítica literaria que, de una forma imperfecta y muchas veces en géneros periodísticos híbridos (Bernardo, 2015: 52-54), «había comenzado en la Ilustración dieciochesca en las tertulias y en las Sociedades de Amigos del País, pasa a finales del siglo y ya entrado el siglo XIX a los diarios y revistas» (Campos, 2010:49). De entre todos los contenidos de crítica literaria en prensa es la referida al teatro la que con más regularidad se cultivó hasta el punto de ser la única acerca de la cual, según ha demostrado la profesora Rodríguez Sánchez de León en La crítica dramática en España (1789-1833) (1999), se puede trazar una nutrida línea histórica desde los primeros periódicos hasta mediado el XIX. Además - y durante la mayor parte de este siglo - la crítica se encuentra en íntima correlación con la política (Campos, 2010: 51), circunstancia esta a la que Cánovas no es ajeno.

Muy rico en novedades teatrales fue el año de 1849 al que, precisamente, David T. Gies dedicó un capítulo monográfico de El Teatro en la España del Siglo $X I X$; en palabras de este autor fue «año clave en la historia del teatro español» (1996: 145) entre otras cosas por la llegada de nuevos teatros y compañías, el cambio del repertorio con la incorporación de «más obras nacionales y originales» que quitaron protagonismo a las «traducciones y refundiciones» (1996: 145), y por las expectativas despertadas debido a la inauguración del nuevo Teatro Español en la sala del Teatro Príncipe.

A continuación se expone un listado cronológicamente ordenado de los textos sobre teatro de Cánovas en La Patria incluyendo también los títulos de las obras que comentó en cada artículo: aquellas en las que no se menciona ninguna obra de teatro se dedican a reflexiones generales sobre el género dramático. 


\begin{tabular}{|c|c|c|}
\hline TÍTULO & FECHA & $\begin{array}{l}\text { OBRAS CRITICADAS (TEATRO DEL ESTRENO). } \\
\text { AUTOR DE LA OBRA }\end{array}$ \\
\hline «Teatros» & $8-\mathrm{I}-1849$ & \\
\hline «Teatros» & $15-\mathrm{I}-1849$ & $\begin{array}{l}\text { - Los casamientos del día (Variedades). Bayard. } \\
\text { — La casa deshabitada (Variedades). Francisco de Palacios } \\
\text { y Toro. } \\
\text { — Herminia (Variedades). Alejandro Dumas. } \\
\text { —El viaje a América (Príncipe). Arreglo de Ramón de } \\
\text { Navarrete. } \\
\text { — Los amantes de Chinchón (Instituto). J. Martínez Viller- } \\
\text { gas, M. Agustín, G. Romero, E. Asquerino y G. Estre- } \\
\text { llas. } \\
\text { - La pata de cabra (Cruz). Marteinville y Ribié. } \\
\text { - De fuera vendrá quién de casa nos echará (Príncipe). } \\
\text { Agustín de Moreto. }\end{array}$ \\
\hline «Teatros» & $22-\mathrm{I}-1849$ & $\begin{array}{l}\text { - La niña boba o Buen maestro es el amor (Príncipe). } \\
\text { Lope de Vega. } \\
\text { — La vida es sueño (Príncipe). Calderón de la Barca. } \\
\text { — La marquesa de Savannes (Variedades). Arreglo de Lau- } \\
\text { reano Sánchez y Ramón de Valladares. } \\
\text { - La víctima de una visión (Variedades). Arreglo de Lau- } \\
\text { reano Sánchez e Ignacio Bueno. } \\
\text { - La Duquesita (Instituto). Arreglo de Ventura de la Vega. }\end{array}$ \\
\hline «Teatros» & 29-I-1849 & $\begin{array}{l}\text { - Las Guerras Civiles (Príncipe). Eusebio Asquerino y } \\
\text { Eduardo Asquerino. } \\
\text { - Simón el Contramaestre (Cruz). M. Z. Cazurro, L. Olo- } \\
\text { na y L. De Valladares y Garriga. }\end{array}$ \\
\hline «Teatros» & 6-II-1849 & $\begin{array}{l}\text { - Don Fernando de Castro (Variedades). Cipriano López- } \\
\text { Salgado. } \\
\text { - El rey de los primos (Instituto). Mariano de Pina. } \\
\text { - No más muchachas (Instituto). Arreglo de Juan del } \\
\text { Peral. }\end{array}$ \\
\hline «Teatros» & $13-$ II-1849 & $\begin{array}{l}\text { - Flaquezas y desengaños. Manuel Ruiz y Torrent. } \\
\text { - El bufón del rey (Cruz). Arreglo de una novela de } \\
\text { A. Dumas por C. Suárez y M. Zacarías. } \\
\text { - Mi media naranja (Cruz). Antonio Marín Gutiérrez. } \\
\text { - El hijo del diablo (Instituto). Arreglo de una novela de } \\
\text { Paul Feval por Francisco de Paula Montemar. }\end{array}$ \\
\hline «Teatros» & $20-\mathrm{II}-1849$. & $\begin{array}{l}\text { - Las últimas horas de un rey (Príncipe). José María Díaz. } \\
\text { — Marica-enreda (Cruz). Narciso Serra y Juan Dot. } \\
\text { —El Califa de Bagdad (Cruz). }\end{array}$ \\
\hline «Teatros» & 6-III-1849 & -Traidor, inconfeso y mártir (Cruz). José Zorrilla. \\
\hline «Teatros» & 18-III-1849 & -Bernardo (Cruz). Joaquín Francisco Pacheco. \\
\hline «Teatros» & $25-I V-1849$ & $\begin{array}{l}\text { - El sí de las niñas (Español). Leandro Fernández de Mo- } \\
\text { ratín. } \\
\text { - Ginesillo el aturdido (Comedia) Pedro Calvo Asensio. }\end{array}$ \\
\hline «Teatros» & $9-\mathrm{V}-1849$ & \\
\hline
\end{tabular}




\begin{tabular}{|c|c|c|}
\hline TÍTULO & FECHA & $\begin{array}{l}\text { OBRAS CRITICADAS (TEATRO DEL ESTRENO). } \\
\text { AUTOR DE LA OBRA }\end{array}$ \\
\hline «Teatros» & $15-\mathrm{V}-1849$ & $\begin{array}{l}\text { - Marido joven y mujer vieja (Español). } \\
\text { - Ricardo D'Arlington (Español). Alejandro Dumas. } \\
\text { — Nobleza contra nobleza (Drama). José Heriberto García } \\
\text { de Quevedo. }\end{array}$ \\
\hline «Teatros» & 12-VI-1849 & $\begin{array}{l}\text { - Hacer cuentas sin la huéspeda (Español). Francisco Flo- } \\
\text { res Arenas. } \\
\text { — No es oro cuanto reluce (Variedades). Antonio Lozano } \\
\text { y José María de Larrea. } \\
\text { - Juan Bravo el Comunero (Drama). Eusebio Asquerino y } \\
\text { Gregorio Romero. }\end{array}$ \\
\hline «Teatros» & $25-\mathrm{IX}-1849$ & - La Reina Sara (Español). José María Díaz. \\
\hline «Teatros» & $16-X-1849$ & - Antonio de Leiva (Español). Juan de Ariza. \\
\hline «Teatros» & $11-X I-1849$ & -Saúl (Español). Gertrudis Gómez de Avellaneda. \\
\hline «Teatros» & 20-XI-1849 & $\begin{array}{l}\text { - Un paje y el Caballero (Drama). Heriberto García de } \\
\text { Quevedo. } \\
\text { - A un tiempo amor y fortuna (Español). Rafael Milán y } \\
\text { Navarrete. }\end{array}$ \\
\hline «Teatros» & 26-XII-1849 & $\begin{array}{l}\text { - ¿Quién es ella? (Español). Bretón de los Herreros. } \\
\text { —Los amantes de Teruel (Español). Eugenio de Hartzen- } \\
\text { busch. } \\
\text { —Las jorobas (Variedades). Mariano Zacarías Cazurro. }\end{array}$ \\
\hline
\end{tabular}

\section{Motivos constantes en los teatros de Cánovas}

El conjunto de artículos y sus contenidos permiten ofrecer una síntesis de la visión que el joven Cánovas tenía sobre el género dramático. En las siguientes páginas se citarán los criterios de juicio que con más frecuencia aparecen en estas críticas y que, según se especificará en las conclusiones, permiten elaborar un retrato del pensamiento canovista de aquellos años.

\subsection{La recuperación del espíritu nacional}

Aunque, como se verá en los siguientes puntos, Cánovas elaboró en $L a$ Patria toda una «teoría del teatro», el elemento de juicio más determinante en sus críticas no obedecía propiamente a criterios de estilo o de técnica sino más bien a criterios histórico-políticos y, más concretamente, a los propios del liberalismo moderantista de su autor. Toda la crítica de Cánovas se enmarca perfectamente dentro de la transición señalada por Juan Carlos Rodríguez según la cual en el teatro del los siglos XVI-XVIII se ofrecía «la representación pública de la ideología de lo público» mientras que en los siglos XVIII-XX $-\mathrm{y}$ 
este es el caso de los Teatros - «pasa a convertirse en la representación pública de la ideología de lo privado» (2001:29).

En concreto para Cánovas el género dramático debía reflejar — y por tanto debía ayudar a construir - lo que se denominaba «espíritu nacional», idea que se desarrolla ampliamente en la crítica a El sí de las niñas. Si el teatro estaba en crisis - y él así lo creía - era debido a que había abandonado la senda de lo español, había renegado — dirá en esa crítica — «de sus antiguos principios, doblando la cerviz al yugo que vino a imponerla el arte extranjero» (25/4/1849). Desde su primer artículo expresó su intención de hacer una «crítica imparcial y concienzuda» basada en la idea de que el teatro estaba vacío de españolidad y de que era necesario volver a ella (8/1/1849).

Para salir al paso de la decadencia proponía que se recuperase el orgullo nacional volviendo la mirada a la tradición. Se apoyaba, como era frecuente en la crítica de la época, en las teorías de Schlegel cuando afirmaba que los pueblos que no habían olvidado su pasado glorioso eran los que poseían verdadera fuerza poética:

No hay poesía, dice Schlegel, sino allí donde se encuentran tradiciones, no podrá cobrar vuelo el arte sino en los pueblos que conservan un pasado grandioso: nosotros estamos de acuerdo enteramente con esta verdad profunda del pensador alemán $(20 / 2 / 1849)$.

Había que beber de las fuentes de la tradición española, que Cánovas cifraba en los valores religiosos y sociales conservadores y en un cierto concepto de nobleza y honor caballeresco:

Nosotros poseíamos la fe pura y sencilla como ningún otro país la tenía; en nuestro pueblo existía aun esa palabra tan poética como destituida ya de valor propio: la lealtad; nuestros proletarios guardaron de las Corporaciones extinguidas los recuerdos más dulces de la caridad y de eso que ahora se llama filantropía. Es también indudable que se mantuvieron vivas en el ánimo de los españoles las reminiscencias caballerescas y heroicas, para no perecer hasta tiempos muy cercanos, si es que han llegado a desaparecer del todo; tenía algo el amor de nuestros galanes de religioso entusiasmo de la edad media; se conservaba cierta dignidad en las familias, cierta poesía en los matrimonios, desconocidas en las otras partes de Europa (8/1/1849).

Era, por tanto, necesario que no hubiera ruptura entre pasado y presente, que se estableciera continuidad entre la que él señalaba como tradición literaria española - representada fundamentalmente por el teatro del Siglo de Oro-y el teatro del momento, por eso invitaba a conciliar la tradición con las transformaciones de la modernidad. Así lo expresaba en crítica la El sí de las niñas:

Calderón y Lope de Vega son los representantes legítimos de la literatura dramática española, el eco de su civilización, la antorcha de su porvenir literario. Con- 
certar los recuerdos que de ellos nos quedan con las modificaciones sociales que hemos sufrido en los últimos tiempos, he aquí la verdadera misión del poeta dramático, esto es lo que exigiremos nosotros de todas las obras nuevas (25/4/1849).

De acuerdo con este elemento de juicio en los artículos se elabora una historia de las luces y las sombras del teatro español. Historia que se sustancia en que al gran fogonazo que suponen los «grandes dramáticos del siglo XVII» le sucede una oscuridad solo interrumpida de manera excepcional por algunos autores. Cánovas salvaba al Moratín de El sí de las niñas:

La musa de Moratín encontró inspiraciones todavía sin salir del suelo patrio: español era el grave y noble don Diego, españolas eran las preocupaciones de doña Inés, española era también Paquita, la niña salida de un convento para sacrificar su hermosura a las razones de conveniencia, sin un pensamiento siquiera de rebeldía $(25 / 4 / 1849)$.

Y reconocía además la existencia de algunos chispazos de «nacionalidad brillantes, suspiros de nuestra gloria que se han dejado oír de vez en cuando, perdidos entre el estruendo impío de la jerga extranjera» de la mano de autores como Espronceda, Gutiérrez, Hartzenbusch, Zorrilla y Rubí, que habían «hecho sin duda todo lo que podía exigirse de ellos». Sin embargo estas habían sido «excepciones, y nada más que excepciones» (8/1/1849).

Una manifestación de esta concepción del teatro son las repetidas denuncias hacia lo que se consideraba pruebas del abandono de la tradición. Le irritaba especialmente que los autores tiraran piedras sobre el tejado español maltratando a grandes personajes de la historia, con especial enfado hacia las obras que atentaban contra el sentimiento monárquico de los españoles -elemento este esencial en la ideología canovista-, a las que llegó a calificar como «imbéciles parodias reales, fraguadas en mal hora para descrédito de la institución» (8/1/1849) refiriéndose a Lucrecia Borgia de Victor Hugo y a Margarita de Borgoña de Dumas, conocidas del público porque escarnecían a la monarquía con la típica exageración romántica.

Al hablar de Las últimas horas de un rey, obra en donde la figura de Felipe II inspiraba «repugnancia»y «vergüenza», Cánovas acusaba a su autor de inferir «una herida más en nuestras tradiciones gloriosas» y de arrancar «otra hoja del árbol ya exhausto de nuestro orgullo», para acabar deseando que «no se manche el recuerdo de lo que fuimos, no se calumnien las glorias que nos legaron nuestros padres». Y todo ello porque Felipe II «bueno o malo es una de las figuras más grandes que presenta la historia; justiciero o verdugo su estatura es de gigante» (20/2/1849). Obsérvese que el autor de las críticas integra en su concepción de lo literario su propia concepción política - y la del medio en el que escribe - frente al liberalismo progresista y al republicanismo. Por el contrario, en la ya citada crítica programática del 8 de enero, invitaba a poner en escena personajes sacados de modelos españoles: «que España dé 
héroes a sus tragedias, y personajes a sus comedias. [...] La primera condición del autor español es poner en escena tipos españoles» (8/1/1849).

En otras ocasiones se quejó de que el público no apreciase el patriotismo en el teatro y así lo manifestaba, por ejemplo, al señalar el escaso éxito de la tragedia Bernardo de Joaquín Francisco Pacheco. A Cánovas le indignaba que «un héroe que se sacrifica por su patria, no conmueve ni arrebata la atención más que a un escasísimo número de espectadores. [...] ¡De otra manera hubiera contestado el público si en vez de presentarse un hombre que salva la patria del extranjero, hubiera venido a la escena un demagogo a decir denuestos a un monarca, un desesperado cualquiera a maldecir a la sociedad, bajo las mil formas con que esto se representa todos los días en nuestros teatros!» (18/3/1849). Y con ardor casi épico resumía así el valor de Bernardo como símbolo nacional:

El punto de partida más brillante que recordamos haber visto en el teatro: una nación que comienza a brotar de sus ruinas, está a punto de perecer otra vez bajo la cuchilla agarena: dos medios de salvación se presentan; el uno es la infamia, el otro es la pelea desigual y peligrosa: elígese este último extremo, y todo el que siente latir un corazón de patriota se entusiasma, porque aquella nación es España y el que ha preferido la gloria a la vergüenza, es Bernardo del Carpio, el héroe de sus romances y de sus consejas (18/3/1849).

Desde esta perspectiva se pueden comprender las quejas por la escasez de estrenos de obras originales y el exceso de adaptaciones de obras extranjeras que, además, solían estar mal traducidas. En las críticas se alude directamente a las traducciones de Dumas, Víctor Hugo y Scribe, a las que se calificaba como «absurdos dramas franceses» (15/1/1849). En otra ocasión, al poco de inaugurarse el Teatro Español, se volvía a hacer hincapié en este desolador panorama: «La mitad de las piezas ejecutadas son francesas, no así comoquiera, sino malísimas comedias que se conservan en su prístino idioma, a pesar de ejecutarse en el Teatro Español por antonomasia» (9/5/1849).

Un ejemplo emblemático de este panorama es la obra la Pata de Cabra, representada repetidas veces a lo largo del año 49: «de piezas ya conocidas ha llegado a representarse últimamente hasta la Pata de Cabra» escribía Cánovas el 15 de enero. Era una traducción-adaptación bastante libre de la obra francesa de Marteinville y Ribié titulada Le Pied de Mouton, comedia de magia titulada en castellano Todo lo vence el amor o La Pata de Cabra, que tuvo un éxito asombroso desde su estreno en 1829 y que fue la obra más representada en el período que va desde 1829 hasta 1850 con «más de doscientas setenta y siete representaciones» (Grimaldi, 1986: 29). 


\subsection{El teatro como expresión de valores universales}

Otro criterio de juicio en las críticas canovistas es el de buscar en las obras la expresión de ideas como la belleza y la justicia. El joven crítico explica que, con independencia del momento histórico en que fueran escritas, con independencia del estilo y del género literario, toda obra de arte es tal si consigue transmitir belleza. Más concretamente consideraba que era labor del crítico «relacionar las obras literarias con el espíritu científico y social de la época, con la marcha de la civilización, y la idea absoluta de la perfección en lo justo y en lo bello» (6/3/1849), es decir, había que fijarse en cómo la obra literaria captaba el latido del presente y relacionarlo con los valores absolutos y eternos. Ejemplos de autores que, según Cánovas, lo habían logrado eran Goethe, Dante, Virgilio, Schiller, Voltaire y Lamartine.

En los Teatros se expone esta idea una y otra vez en términos muy parecidos y, por ello, no es sencillo saber a qué se refiere exactamente con «transmisión de valores universales» o con «el valor absoluto de la belleza». Cuando trata sobre ello teóricamente parece referirse a la belleza como un valor estético universal que permitiría juzgar el arte de acuerdo con el grado de parecido a ese valor ideal. Sin embargo es preciso atender a cómo ejerce los juicios críticos para advertir que en este caso, al igual que en el anterior, lo que de hecho se juzga no es el estilo o la forma sino los contenidos. Las obras, según las críticas de Cánovas, son mejores si transmiten un criterio de moralidad que pueda ser imitable; al hablar del valor universal de la belleza Cánovas se refiere a la belleza que se desprende de una obra bien hecha, la hermosura de un ejemplo de comportamiento justo.

Al comentar, por ejemplo, la tragedia Bernardo de Joaquín Francisco Pacheco insistió en que «cualesquiera que sea el género, cualesquiera que sean las formas de una obra de arte, sus cimientos deben hallarse en lo absoluto y en lo reconocido universalmente» (18/3/1849) y, según este criterio, Bernardo era magnífica porque exaltaba valores como la nobleza o la lealtad.

En cambio, de Traidor, inconfeso y mártir — con palabras atrevidas porque se trataba de la obra de un reputado dramaturgo - afirmó que no encarnaba altos pensamientos porque «Zorrilla no sabe dónde va». Y añadía: «no busquéis en él criterio alguno [...] su espíritu no tiene alas para elevarse al lazo común de las ideas y de los pensamientos del siglo» (6/3/1849). El valor de Zorrilla se ceñía a la parte artística, que era otro de los criterios para enjuiciar el hecho teatral, tal y como se verá en el apartado siguiente.

Este criterio del valor del teatro como expresión de lo universal se aplicaba también a aquellas comedias de costumbres que manifestaban un profundo conocimiento del hombre retratando tipos que, por trascender lo circunstancial y calar en lo esencial del comportamiento humano, estaban siempre vigentes. En esas obras siempre se debía presentar lo bueno como ideal y lo malo como 
reprobable, tal y como habían hecho Lope en La niña boba y Moreto en De fuera vendrá quien de casa nos echará:

Si los caracteres de estas comedias están fundados en un estudio verdadero del corazón humano y en la observación íntima de las costumbres y en el análisis de los principios esenciales de la sociedad, seguramente podrán ser aplaudidas por hombres de todos los siglos, de todas las naciones, de todas las creencias. Siempre ha habido por ejemplo viejas enamoradas, nunca han faltado pisaverdes superficiales, y niñas traviesas, avaros, celosos y pedantes; son caracteres eternos que corresponderán en todas los tiempos a ciertos tipos sociales $(22 / 1 / 1849)$.

Y concluía que esa era la razón por la que «las comedias de nuestro teatro antiguo que pertenecen a este género producen siempre buen efecto» (22/1/1849).

\subsection{Estilo y verosimilitud}

Dos elementos que debían estar presentes en las críticas eran el juicio sobre la verosimilitud de la trama y sobre la calidad y oportunidad de las versificaciones. Con respecto a lo primero Cánovas dedicó especial atención en sus Teatros a los desencadenantes de cada acción, a la lógica de la narración dramática. Pero también entendía la verosimilitud como coherencia con el momento histórico en el que esta se desarrollaba. Por ello rechazaba las exageraciones románticas que descuidaban la coherencia del relato tanto como las incoherencias históricas en la línea del patriotismo ya señalado.

Los ejemplos son muy numerosos y tan fino era el tamiz de su crítica que lo aplicó sin ningún reparo a Zorrilla en el estreno de Traidor, inconfeso y mártir:

No están claros ni justificados los diferentes resortes del drama. El rey don Sebastián se ignora si emprendió o no para conspirar su viaje, si tenía ambición o generosidad: la bula misma de excomunión no se sabe por qué viene con certeza; el morir inconfeso no alcanza a disculparlo la razón pueril de que no podía descubrir quién era: ignoramos que la confesión empiece nunca por preguntar el nombre ni el apellido (6/3/1849).

Los ejemplos se multiplican en la misma línea: no todo está justificado en la escena; debe haber una coherencia en los personajes, en la época escogida y en el desarrollo argumental. Así lo destacó en la crítica de la Herminia de Alejandro Dumas:

Tiene la pieza sin duda escenas interesantes, pero las hay tan inverosímiles, que luchan abiertamente con la historia y con el buen sentido. Que un amante desafíe a su rival y que éste no admita el duelo (en la corte de Luis XIV a lo que parece), no es creíble por poco que se hayan ojeado los cuadros de costumbres del propio Dumas. El marqués no hubiera rehusado por cierto y más siendo hombre que se 
había batido ya doce veces nada menos, y el amante debiera haber insistido algo más para mantenerse a la altura de su desesperación... (15/1/1849).

Cánovas anhelaba encontrar naturalidad en las tramas y no dejaba de señalar los aspectos que iban contra ese discurrir razonable de los sucesos; sobre la comedia La casa deshabitada de Francisco Palacios y Toro señalaba que «la careta y traje de máscara para el novio se encuentran allí más a mano que conviene en los buenos recursos dramáticos; el súbito soborno de los criados para que griten fuego, es inverosímil» (15/1/1849). Las acciones debían de tener una justificación, según señalaba acerca de Saúl de G. Gómez de Avellaneda: «Es que Saúl se ve perseguido y condenado a terribles desgracias sin un motivo evidentemente grande: que no aparece merecedor de su suerte desgraciada: que por consiguiente, ni la trama presenta interés ni el desenlace se presenta bien justificado» (11/11/1849).

Además, era este un criterio que cualquier espectador podría apreciar por cuanto lo que el teatro debía era mostrar lógicas de comportamiento habituales: «Presentan en la escena - afirmaba a propósito de Marica-enreda de Narciso Serra y Juan Dot - personajes ridículos y absurdos que apenas hallarían originales en nuestra sociedad» (20/2/1849).

En Las guerras civiles ${ }^{4}$, de Eusebio y Eduardo Asquerino (29/1/1849), los protagonistas eran dos hermanos, Carlos y Luis, que se enfrentaban por motivos políticos — cada uno era partidario de un príncipe que luchaba por el trono-y por motivos sentimentales — amaban a la misma mujer - . Si la primera pugna era razonable, la segunda no convencía al crítico. El sentimentalismo desbordado estaba muy de moda en el teatro de la época pero a Cánovas le irritaba por lo que tenía de recurso fácil y porque quitaba importancia a los móviles políticos como motor de la acción dramática:

¿Por ventura hacen falta aquellos amores en la acción? No, por cierto. Y sea cualquiera la tendencia de nuestro siglo a ver siempre el amor en las tablas, todavía creemos nosotros que podía pasarse sin él excitando otras pasiones, moviendo otros intereses. [...] No son indispensables los requiebros amorosos en dramas de altos caracteres. [...] Para pintar los daños de la guerra civil debió presentársela desnuda ante los espectadores, sin ayuda de otro sentimiento $(29 / 1 / 1849)$.

En la crítica del drama histórico Antonio de Leiva, Cánovas dedica la mayor parte del texto a reconstruir y recordar hechos y rasgos de la época en la

${ }^{4}$ El trasfondo político de Las guerras civiles era la Guerra de Sucesión. La disputa se abordaba con recursos trágicos y con un multifacético e intrincado significado simbólico (Ginger, 2000) que Cánovas sin duda rechazaría. Sin embargo en esta crítica se limita a hacer observaciones sobre la verosimilitud de la trama y sobre la versificación. 
que está ambientado, el siglo XVI, para luego afirmar pesaroso que ninguno de estos elementos está presente en el drama de Juan de Ariza.

Junto con el análisis de las tramas, en los Teatros se hace alusión al estilo, centrado prácticamente en exclusiva en la calidad de la versificación. El criterio del juicio de Cánovas con respecto a los versos no es claro $\mathrm{y}$, de todos los aspectos de la obra a los que se refiere, es el que contiene un elemento subjetivo superior. Por un lado se valora que los versos sean adecuados a la clase de obra de la que se trata: si la acción es trágica alabará la «altura trágica»y, por el contrario, cuando se usa un lenguaje altisonante sin que el contenido lo requiera, se señalará aquello como un fallo. De Saúl, de Gómez de Avellaneda, se deshizo en elogios: «las escenas están muy bien trabadas unas con otras, [...] la versificación es tan buena que apenas recordamos otra que la iguale en nuestro teatro moderno» $(11 / 11 / 1849)$.

Sin embargo, la versificación de los hermanos Asquerino era «sonora» pero con algo de «afectación» e imitaban a Calderón y a Lope en sus «alambicadas relaciones» y en «los resabios de la mala escuela de Góngora» (29/1/1849). Y en Las últimas horas de un rey «falta interés en la acción, falta movimiento en la escena, $[\ldots]$ todo está dicho a medias, todo sin acabar de pintar las figuras...» (20/2/1849).

A la vez criticará la reiteración en los versos de algunos autores y, por el contrario, alabará la frescura en los cambios de estrofa. Magnífica era la versificación de Bernardo de J. F. Pacheco, «elevada» y «sonora», y el autor, «introduciendo la variedad de metros, ha alejado de su obra la monotonía insufrible del endecasílabo aconsonantado, sin que el estilo pierda por eso nada de su energía ni de su grandeza trágica». Y continuaba con más alabanzas a la forma: «La elevación del estilo, la regularidad de la acción que camina desembarazada a su fin, siempre sostenida y siempre verosímil, pero sin extrañas peripecias, sin movimientos sorprendentes ni transiciones violentas» $(18 / 3 / 1849)$. El crítico alaba la naturalidad entre contenido y forma y denuncia lo que entiende que es impostación. De Ginesillo el aturdido, por ejemplo, decía que tenía «versos durísimos, ripios indisculpables, tiradas de versos que parecen hechos con solo el objeto de llenar una comedia en tres actos» (25/4/1849).

Al hablar de Zorrilla recuérdese que Cánovas censuraba la poca verosimilitud de sus obras y la ausencia de ejemplaridad en ellas sin embargo lo que las salvará es su «frescura» conseguida por medio de una versificación dinámica. Zorrilla no es buen constructor de dramas pero sí un mago de los versos:

Zorrilla canta porque ha nacido poeta; hombre de forma puramente, no le preguntéis de dónde saca sus cantares, ni cuáles son sus dogmas literarios: cantar, cantar; he aquí su misión única a lo que parece; he aquí el solo destino que le complace [...] Pero Zorrilla es admirable en su anarquía, tiene el privilegio de que sean bellas sus aberraciones [...] ¡Con qué bizarría presenta su acción en la escena! ¡Qué exposición tan interesante! ¡Qué golpes calderonianos tan oportunos! ¡Qué mágica armonía la de sus versos! ¿Qué colorido tan perfecto en sus cuadros! El 
señor Zorrilla, ¿quién puede dudarlo? es uno de los ingenios más lozanos que ha alcanzado nuestra literatura: fáltale mucha meditación y no poco estudio, pero todo ello suele suplirlo a fuerza de talento. [...] Con nombrar al autor, dicho se está su inimitable numerosidad y armonía [...] iqué mágica armonía la de sus versos! (6/3/1849).

\subsection{El teatro como escuela de buenas costumbres burguesas}

Se ha hablado de la necesidad de que las obras transmitieran la hermosura de valores universales tales como justicia y lealtad. Pero es preciso dedicar un epígrafe a su convencimiento de que el teatro debía transmitir la forma en que habían de hacerse presentes esos valores. Desde la primera de sus críticas, la del 8 de enero, pone en valor su fe en la gran influencia del teatro en las costumbres sociales y la importancia de advertir al espectador acerca de la «predicación de doctrinas extrañas con que se derrama en el pueblo inexperto la anarquía de las ideas y de los sentimientos» (8/1/1849). Dos semanas después insistía en la vigencia de la comedia de costumbres aduciendo que en cualquier época habrá hombres cuyos defectos puedan ser ridiculizados: afirmaba que las comedias «que representan y ridiculizan esta o la otra manía, tal preocupación o vicio», como La niña boba, solían ser bien acogidas en todos los tiempos porque «siempre existen algunos tipos con que relacionarlas» (22/1/1848). A través de las críticas Cánovas desvela un sentido moral alejado de cierta sensibilidad romántica propensa a exageraciones y desvaríos, y cercano a una nueva sensibilidad burguesa, más serena, equilibrada y racional.

El 13 de mayo afirmaba que había «dos principios que es fuerza conservar a toda costa: la familia y la propiedad. [...] Esos grandes deberes de que hemos hablado, la familia y la propiedad, hay, pues, gran peligro en representarlos conculcados y escarnecidos». La defensa de estos valores conservadores le llevó a lamentar que Ricardo D'Arlington de Dumas, a pesar de tener aspectos positivos, dejase mucho que desear en cuanto a valores morales, por eso pedía que «si no se moraliza, que no se corrompa, al menos, la sociedad con el teatro; si nada nuevo se enseña, que no se disipen tampoco las viejas tradiciones de lealtad y los instintos populares de justicia» (13/5/1849).

Cánovas insistía en estos puntos en la mayoría de sus críticas como resultado de su convencimiento de la gran influencia que el teatro tenía sobre las costumbres y de su importancia en la educación del pueblo. Solía prevenir a sus lectores de la corrupción que podía llegar a través del teatro: «No hay cosa más fácil, dice Schlegel, que pervertir a una sociedad por medio del teatro: no es sin embargo muy honroso el papel de los que lo ejecutan» (22/1/1849). La tragedia de José María Díaz, La reina Sara, estaba protagonizada por tipos anómalos, que cometían adulterios, incestos, traiciones y asesinatos. La protagonista representaba «un sensualismo brutal»; en su carácter se perdía «toda hilación [sic] moral; fuera del camino lógico de la criminalidad humana, se 
presenta como un aborto de la naturaleza»(25/9/1849). Y en la comedia $E l$ viaje a América «se ponen en befa los sentimientos más respetables» (15/1/1848).

En la línea de salvaguarda de los valores familiares tradicionales, Cánovas arremetió contra aquellas obras que presentaban conductas aberrantes como Traidor, inconfeso y mártir donde se presentaba a la joven Aurora renegando de su padre, algo que — según Cánovas - «pertenece a las pasiones abyectas de la materia, al aniquilamiento de toda creencia [...] escarnio del amor paternal»» $(6 / 3 / 1849)$.

En el texto que dedicó al Bernardo de Pacheco estallaba su indignación al referirse a las lacras típicas de obras románticas que había visto exaltadas en los dramas recientemente estrenados, entre ellos el anterior de Zorrilla, al que se refiere en primer término:

Una hija que maldice a su padre es aplaudida — la sociedad actual lleva ya con impaciencia hasta el freno de la familia-, una adúltera que abandona a su marido, encuentra simpatías harto copiosas, que no es nuestra época de las que santifican ningún vínculo; al suicida que maldice la vida se le escucha con afecto; al revolucionario que combate toda autoridad se le admira y se le justifica (18/3/1849).

La función pedagógica del teatro también abarcaba las críticas a los detalles de mal gusto, vulgaridad y chabacanería que se veía en el escenario. En Los casamientos del día, había «escenas de mala educación, sin más que por presentarlas» y en Los amantes de Chinchón - parodia de Los amantes de Teruel-, «abundan equívocos de no muy buen género, circunstancias como la del zapato, que no por groseras tienen chiste alguno» (15/1/1849). Se refería al episodio en el que un personaje le contaba a Ruperta, la protagonista, que su amado Diego, en manos de los turcos, había muerto por haberse entendido con la mujer de un bey, y como prueba le entregaba el objeto que Ruperta le había dado en prenda antes de su marcha: un zapato.

Cánovas defendía que, incluso para construir comparaciones que expresasen pensamientos triviales, había de guardar cierto decoro y el del zapato resultaba un resorte teatral vulgar y zafio, «profanaciones odiosas de los sublimes versos con que asombró el Sr. Hartzenbusch su comedia» (15/1/1849). Le resultaban también ofensivas expresiones como la de «viejo salido», usada por una esposa celosa para referirse a su marido (6/2/1849).

\subsection{La puesta en escena}

Un último aspecto presente en las críticas es el del juicio a la propia representación de la obra y al teatro mismo. Para escribir los teatros Cánovas tiene en cuenta los textos pero también la puesta en escena y las actuaciones. No debe perderse de vista que se trataba de artículos de periódico orientados a que el público fuera o dejara de ir a una función. Esta vez sus tesis son menos 
interesantes de cara a la elaboración de un pensamiento literario, sobre todo si se tiene en cuenta que estas consisten en comentarios en los cuales, en general, el sentido común es la norma y no tanto una peculiar teoría sobre la actuación.

Y esto es así porque la calidad media de las representaciones era muy defectuosa. Los testimonios a este respecto son unánimes; García Castañeda, por ejemplo, constata que, en lo que se refiere a los actores, el vestuario y los apuntadores, «parece que eran vicios comunes entonces el agruparse junto a la concha del apuntador para oírle mejor; el hablar con el público y no con el interlocutor en escena; el quedarse inmóvil como una estatua cuando no correspondía hablar. En el Teatro del Museo, por ejemplo, los actores eran malos, las piezas se representaban mal ensayadas y la voz del apuntador se oía en la sala» (1971: 57).

Con respecto a los actores Cánovas valoraba por encima de todo su manera de hablar y lo que en lenguaje actual se llamaría «profesionalidad». Consideraba que «en nuestra obligación de críticos nos vemos precisados a decir la verdad a estos actores que bien pudieran mejorarse con esmero propio y buen estudio de sus papeles» (13/5/1849). No dudó en señalar los defectos de dicción —un «cierto seseo»— en Los casamientos del día (5/1/1849) y la poca profesionalidad de los actores en el escenario en Los amantes de Chinchón:

No dejaron de sorprendernos las risas de los actores de ambos sexos, que a veces tuvieron que cortar la representación por ella. Creemos que esta debilidad fue lo único que aplaudió el público en toda la pieza, y a no advertir ellos por tal modo, que en tal y tal lugar había chiste, hubiera pasado desapercibido para nosotros $(15 / 1 / 1849)$.

Las críticas a la falta de «profesionalidad» tenían en común los reproches a aquellos actores que no se sabían su papel y debían acudir al apuntador. Los comentarios sobre los apuntadores fueron muy mordaces. Estos eran poco discretos, por eso Cánovas rogaba irónicamente a alguno «que moderase un tanto los impulsos de su pulmón, pues a la verdad más se le oye a él que a los actores» (15/1/1849). Especialmente detallado es este largo comentario en donde se muestra inusualmente mordaz:

Sin duda que esta revista debe comenzar por los apuntadores, a haber de seguirse en ella el orden marcado por los hechos teatrales. [...] Los apuntadores... de estos debe ser la frasecilla castellana que dice: nos oirán los sordos pues si en cualesquiera otra clase de personas puede pasar por impulso ciego de la cólera y ponderación o fanfarronada de imposible efecto, en ellos alcanza indudable verdad y tiene ejecución cumplida (que ojalá no la tuviera) como puede verlo cualquiera que por desgracia suya, cediendo a los arranques de su natural generoso, o a las prescripciones del galanteo aristocrático, tome luneta principal en el Príncipe o butaquilla en el Instituto o asiento privilegiado en Variedades. Desde allí tendrá el placer de oír dos veces la comedia, que es cosa de dar dos veces el dinero de 
puro gusto; rectificará de por si propio las equivocaciones de los actores, que no es poco $(22 / 1 / 1849)$.

Pero también abundaron las alabanzas a los actores, sobre todo a aquellas figuras inmortales que contribuyeron a dignificar esa profesión que tan desprestigiada estaba entonces: "La señorita Montero estuvo en la ejecución inimitable y mereció que se la llamase después de la representación» (22/1/1849); el matrimonio de actores formado por Matilde Díez y Julián Romea fueron el atractivo fundamental de algunas obras de teatro:

Matilde nos dejó algo que desear en el prólogo; pero en lo demás del drama se mostró inimitable: Julián Romea estuvo desde el principio hasta el fin como pocas veces le hemos visto [...]. El señor Ariza ha obtenido un triunfo indisputable; más justo es que le asociemos en él a los actores (16/10/1849).

En la representación de Ricardo D’Arlington, la ejecución de los actores fue tan buena que podía ser «peligrosa», porque «podrían hacernos amar el género por poco que apartásemos de nosotros las altas cuestiones de moralidad y de porvenir que nos obligan a rechazarlo» (13/5/1849). En el Bernardo, en cambio, ninguno de los actores «se ha puesto en su representación a la altura de la tragedia; que solo el señor Latorre, evocando sus recuerdos de hace veinte años, mantuvo en alguna que otra ocasión la dignidad de la pieza que se representaba» $(18 / 3 / 1849)$.

Además de alabar o criticar la profesionalidad de los autores y de denunciar la labor de algunos apuntadores, Cánovas criticaba algunas prácticas en las funciones. Por ejemplo la costumbre, relativamente reciente, de que los autores fueran llamados a escena al final de las representaciones de éxito para recibir el aplauso del público. Esta costumbre se había puesto de moda en 1836 cuando el público reclamó la presencia del desconocido autor de El Trovador y se venía abusando de ella por parte tanto del público como de los autores, de ahí la frecuencia de los comentarios irónicos de Cánovas:

El señor Vega dio en este punto una lección bien merecida a los gritadores de teatro que han tomado por imprescindible consecuencia de una representación buena o mala, original o traducida el llamar al autor a las tablas. Aplaudimos el buen gusto del señor Vega en no haber salido a las tablas; su nombre, que tanta gloria merecida ha alcanzado y debe alcanzar en lo sucesivo, no hubiera ganado nada con la ovación del sábado en el Instituto (22/1/1849).

Y en otra ocasión:

Y ya que la costumbre exige ahora que al fin de toda función nueva se presenten los autores en las tablas, desearíamos que no se repitiese la tal escena en todas las representaciones. Si esto fuera así aconsejaríamos a los autores que se estima- 
sen a sí mismos, que dejasen de asistir a los teatros para no seguir formando parte del espectáculo (29/1/1849).

En aquella época el comportamiento escandaloso y grosero del público durante las representaciones - sus reacciones y sus gestos- era algo harto documentado, y también fue objeto de la crítica de Cánovas, quien aguijoneó repetidas veces al espectador para educarle en el buen gusto: «el público que aplaude estas cosas [inmorales] da peor idea de sí que el autor que las emplea pro pane lucrando» (22/1/1849). A propósito de la representación del sainete No más muchachas, Cánovas reprochaba a los asistentes que hubieran hecho «repetir aquellos saltos al pobre señor, sin más que por oírle decir, estoy fatigado con todas las veras de su alma» (6/2/1849).

En la crítica del 6 de febrero se refirió a los «mosqueteros», grupo especialmente ruidoso en la manifestación de sus gustos y disgustos en el teatro. Eran los que más adelante se llamarían «alabarderos» (Díez Borque, 1988: 606) y que con ocasión de la representación de El rey de los primos «dejaron deslizar de sus labios, aunque tímidamente por falta de costumbre, cierto sonido puntiagudo que más quería parecer silbo que no muestra alguna de aprobación o de gusto» (6/2/1849).

Por último, Cánovas solía hacer referencia al estado de los locales que, por lo general, era lamentable: suciedad, malos olores, manchas de aceite en la ropa por culpa de los candiles, etc. El recinto del Teatro Variedades le producía verdadera repugnancia:

El aspecto miserable del patio, las ínfulas de palomar de los pisos altos, la lóbrega caverna donde concurren las gentes menos acomodadas y que forma e extremo opuesto al escenario, el alumbrado escaso y de candil, la música de murga, las decoraciones absurdamente impropias (12/6/1849).

En cuanto al recién inaugurado Teatro Español Cánovas alabó las «butacas forradas acaso con demasiada riqueza, un techo bellamente pintado, algunos buenos retratos, mejor alumbrado que antes, muchos adornos dorados, repartimiento oportuno del local, buen gusto, en fin, en casi todas las obras ejecutadas $\mathrm{y}$ aun algunos adelantos, si no tantos como deseáramos, en punto a maquinaria y decoraciones...» (9/5/1849).

\section{CONCLusiones}

Los criterios críticos señalados forman una sinfonía: cualquier obra de teatro debería transmitir, a la vez, la altura de lo español, ser un espejo de grandes virtudes y tener un estilo adecuado a ellos, ni demasiado exagerado ni monótono. Junto con esto todas las obras deberían coadyuvar a la formación de una sociedad de costumbres moderadas, una sociedad realista (que en el 
imaginario de Cánovas quiere decir una sociedad burguesa, de clase media). Y las obras debían de tener una representación digna en las tablas. Hay en sus críticas, pues, un clima de búsqueda de la naturalidad liberal moderada que, más allá de la verosimilitud, es una búsqueda de armonía entre todos los aspectos, una anhelo de equilibrio.

Leídos en su conjunto se pueden extraer conclusiones de muy diversa índole. En este epígrafe se citarán las tres más sustanciales. Todas ellas, como se verá, son perspectivas diversas de un mismo pensamiento y por tanto guardan una cierta coherencia:

a) Un primer elemento que sorprende al lector es la madurez crítica de Cánovas a pesar de su juventud. Esta madurez se puede advertir, por un lado en la erudición que manifiesta en estos textos, sustanciada, por ejemplo, en el amplio abanico de observaciones históricas acerca de los momentos en los que se desarrollaban las obras así como el manejo de las referencias más habituales en la crítica de esos años — desde Aristóteles hasta Schlegel— que se citan con naturalidad.

Pero la madurez también se advierte en la clase de pensamiento literario-político transparentado por el autor. En su gusto por la moderación como un presupuesto intelectual, en la búsqueda de las buenas costumbres, en su afán por juzgar las obras de acuerdo con la moralidad que expresan y, en fin, en el uso de un criterio final de belleza estética según el cual el gusto del crítico es definitivo, demostrando con ello una notable confianza en sí mismo. Este pensamiento, que parece corresponder a la psicología de alguien mayor, lo mantuvo Cánovas, con mínimas variaciones, a lo largo de su vida. En su crítica no parece haber evolución sino profundización.

La idea, por ejemplo, del valor del teatro como medio para construir una nación fue una constante en su trayectoria. Dieciocho años después de escribir sus críticas teatrales en La Patria, Cánovas leyó su discurso de ingreso en la Academia Española con el sugerente título de «De la libertad en las artes» (1868b: 115) y en él insistió, entre otros asuntos, en la importancia de la historia nacional como tema literario. Posteriormente, en 1885, publicaría un libro titulado El Teatro Español, en el cual realizaba un recorrido sobre el género dramático en España, desde Lope y Calderón hasta Echegaray; allí se desarrollaba la idea de que el teatro contemporáneo debía recuperar la «poesía nacional» (1885: 101). Ideas ambas que, según se ha visto, ya estaban definidas en el pensamiento canovista de las críticas de 1849.

Es especialmente singular la ponderación como signo de madurez, es decir, la penetración con la que reflexiona sobre el hecho teatral. Cánovas no era un crítico despiadado. Si no le gustaba lo que se transmitía en una obra sí que podían parecerle bien, por ejemplo, la versificación, los giros dramáticos o incluso la manera de engarzar un acto con el siguiente. En este sentido es di- 
fícil que la crítica de una obra fuera enteramente negativa o enteramente positiva.

b) Frente a los criterios que habitualmente se expresaban en las críticas de poesía o de novelas, Cánovas, a la hora de hablar del teatro, no toma posición por una u otra corriente teatral. En este sentido puede decirse que sus valores literarios (reconstrucción del espíritu nacional, verosimilitud, espejo de buenas costumbres, transmisión de belleza) pueden estar presentes en muy diversos estilos.

En esta concepción del teatro tampoco hubo evolución en su pensamiento. Años más tarde, en el citado discurso «De la libertad en las artes», Cánovas desarrolló esta idea ampliamente, al afirmar, sustentándose en conceptos platónicos, que lo verdaderamente meritorio de una obra de arte era su capacidad para expresar lo eternamente bello, logro que — según afirmaba - se había visto encarnado en corrientes aparentemente contrarias como el romanticismo y el clasicismo, porque en ambas hubo arte verdadero: «con lo clásico como con lo romántico, mirado uno y otro en sus aciertos, no en sus respectivos extravíos, se han recogido por el arte distintos aspectos de la belleza eterna» (1868b: 164).

De esta forma, frente a la noción de evolución — noción con la que se ha explicado en no pocas ocasiones toda la historia de la literatura - en el teatro, según trasmite Cánovas, hay una suerte de esencia universal (mesura, verosimilitud, verdad histórica, valores universales) que, de hecho, está presente en muchos estilos y en períodos históricos diversos.

c) En tercer lugar, hay dos notas, íntimamente relacionadas, que se muestran imprescindibles para captar el pensamiento literario del joven Cánovas y para entender sus críticas. Por un lado está la interacción entre pensamiento político y literario, la cual, por cierto, es una constante en las grandes corrientes culturales del siglo XIX. Por otro lado está la concepción del teatro como generador de pensamiento social, la concepción, llamémosla así, didáctica del teatro.

Para Cánovas, el teatro tenía una clara función pedagógica y de utilidad social: debía atenerse a las normas de buen gusto y de respeto a una moral enraizada en la tradición: respeto a la autoridad y a aquellos valores que constituyen la identidad social y política española. El teatro debía ser modelo de buenas costumbres, debía ser moralizante y debía ser formativo. Esto es así hasta el punto de que para Cánovas las obras que no tenían éxito pero transmitían valores universales debían representarse hasta que se «variara» el gusto del público.

Sus «criterios formativos» tenían mucho que ver con una concepción conservadora y moderada, con repercusiones no solo morales sino también políticas. El carácter educativo, por ejemplo, incluía la historicidad de las obras y 
por eso estas debían de ser históricamente correctas y, en lo posible, ambientadas en España. El componente didáctico del teatro es tan fuerte que es fundamental a la hora de enjuiciar, por ejemplo, un drama. Las palabras más duras fueron para aquellos que quebrantaban estos principios. La misión del crítico teatral era ayudar, con una crítica sincera y exigente, a educar el gusto del público y de los autores. En ese sentido si el teatro era trasformador, la crítica también debía serlo. De ahí el tono aleccionador, a veces un tanto pretencioso, que se utilizaba en algunos Teatros.

\section{BIBLIOGRAFÍA CITADA}

Alborg, Juan Luis (1980). Historia de la literatura española, IV. Madrid: Gredos.

Alborg, Juan Luis (1991). Sobre Crítica y Críticos. Madrid: Gredos.

Alonso, Cecilio (2010). Historia de la literatura española. 5. Hacia una literatura nacional, 1800-1900. Barcelona: Crítica.

Bernardo San Juan, José (2015). Críticos y periodistas: historia esencial de la crítica literaria en la prensa (1730-1900). Madrid: Fe d'erratas.

Blanco García, Francisco (1903). La literatura española en el siglo XIX, II. Madrid: Ed. Sáenz de Jubera hermanos.

Bullón de Mendoza, Alfonso y Luis Eugenio Togores Sánchez (1999). Cánovas y su época. Madrid: Fundación Cánovas del Castillo.

Cabrera, Mercedes, Antonio Elorza, Javier Valero y Matilde Vázquez (1975). «Datos para un estudio cuantitativo de la prensa madrileña (1850-1875)», en Prensa y sociedad en España 1820-1936. Madrid: Cuadernos para el Diálogo, pp. 47-148.

Campos Fernández-Fígares, Mar (2010). «La crítica en la plaza pública. Siglos XVIII-XX (pequeñas dudas históricas sobre educación y literatura)», OCNOS: Revista de estudios sobre lectura. 6, pp. 45-60. doi: 10.18239/ocnos_2010.06.04

Cánovas del Castillo, Antonio (1868a). Estudios literarios, I. Madrid: Imprenta de la biblioteca universal económica.

Cánovas del Castillo, Antonio (1868b). Estudios literarios, II. Madrid: Imprenta de la biblioteca universal económica.

Cánovas del Castillo, Antonio (1881). Prólogo a Autores dramáticos contemporáneos y joyas del teatro español del siglo XIX, I. Madrid: Imprenta de Fortanet, pp. I-LXIX.

Cánovas del Castillo, Antonio (1883). El Solitario y su tiempo. Biografía de don Serafín Estébanez Calderón y crítica de sus obras. Madrid: Imprenta de A., 2 vols.

Cánovas del Castillo, Antonio (1885). El teatro español. Madrid: Ibero-Americana.

Cejador y Frauca, Julio (1910). Historia de la Lengua y la Literatura castellana, 7. Madrid: Tip. De la Rev. de Arch., Bibl y Museos.

Celma Valero, María del Pilar (1989). La pluma ante el espejo (visión autocrítica del «fin de siglo», 1888-1907). Salamanca: Ed. Universidad de Salamanca.

Celma Valero, María del Pilar (1991). Literatura y periodismo en las revistas del fin de siglo: estudio e indices (1888-1907). Madrid: Ed. Júcar.

Díez Borque, José María (1988). Historia del teatro en España, II. Madrid: Taurus.

Fabié, Antonio María (1928). Cánovas del Castillo. Su juventud. Su edad madura. Su vejez. Estudio biográfico. Barcelona: Gustavo Gili. 
García Castañeda, Salvador (1971). Las ideas literarias en España entre 1840 y 1850. Berkeley: University of California Press.

Gies, David T. (1996). El teatro en la España del siglo XIX. Cambridge: Cambridge University Press.

Ginger, Andrew (2000). «¿Españoles sobre todo? Eusebio Asquerino y la Guerra de Sucesión», Hispanic Research Journal: Iberian and Latin American Studies. I, 3, pp. 287306. doi: 10.1179/hrj.2000.1.3.287.

Gómez Aparicio, Pedro (1967). Historia del periodismo español: desde la "Gaceta de Madrid" (1661) hasta el destronamiento de Isabel II. Madrid: Editora Nacional.

Grimaldi, J. de (1986). La pata de cabra. D. T. Gies (ed. e introd.). Roma: Bulzoni.

Menéndez Pelayo, Marcelino (1949). Estudios sobre el teatro de Lope de Vega. Crónicas y leyendas dramáticas de España. Santander: Ed. Nacional.

Pacheco, Joaquín Francisco (1864-1865): Literatura, historia y política. Madrid: S. Martín-Jubera, 2 tomos.

Roch, León [Francisco Pérez Mateos] (1927). La Villa y corte de Madrid en 1850. Madrid: Imprenta Hispánica.

Rodríguez, J. C. (2001). La norma literaria. Madrid: Debate.

Rodríguez Sánchez de León, M. ${ }^{a}$ José (1999). La crítica dramática en España (1789-1833). Madrid: CSIC.

Romero Tobar, Leonardo (1994). Panorama crítico del Romanticismo Español. Madrid: Castalia.

Seoane, María Cruz (1996). Historia del periodismo en España, 2. El siglo XIX. Madrid: Alianza.

Seoane, María Cruz y María Dolores Saiz (1983) Historia del periodismo en España. Madrid: Alianza.

Simón Díaz, José (1946). El Semanario Pintoresco Español (1836-1857). Madrid: CSIC.

Viñas Piquer, David (2002). Historia de la crítica literaria. Madrid: Ariel.

Zuleta, Emilia (1966). Historia de la crítica española contemporánea. Madrid: Gredos.

Fecha de recepción: 10 de julio de 2015.

Fecha de aceptación: 13 de mayo de 2016. 